\title{
COMBINATION OF STRETCHING WITH IMMERSION SYSTEM (COLD AND CONTRAST) ON DOMS PAIN TOLERANCE
}

\author{
Sartika D ${ }^{1 *}$, Griadhi IPA ${ }^{2}$, Lesmana $\mathrm{SI}^{3}$, Adiatmika $\mathrm{IPG}^{2}, \mathrm{Karmaya} \mathrm{NM}^{4}$, Dewi NNA ${ }^{5}$ \\ ${ }^{1}$ Magister Program of Sport Physiology Medic and Health Sciences Faculty, Udayana University, 80234, \\ Denpasar, Indonesia. \\ ${ }^{2}$ Department of Physiology, Faculty of Medicine, Universitas Udayana, 80234, Denpasar, Indonesia. \\ ${ }^{3}$ Faculty Physiotherapy, Universitas Esa Unggul, 11510, Jakarta, Indonesia. \\ ${ }^{4}$ Department of Anatomy, Faculty of Medicine, Universitas Udayana, 80234, Denpasar, Indonesia. \\ ${ }^{5}$ Department of Biochemistry, Faculty of Medicine, Universitas Udayana, 80234, Denpasar, Indonesia. \\ E-Mail: menyodonggala@gmail.com
}

\begin{abstract}
Delayed onset muscle soreness (DOMS) is a complaint of muscle pain experienced by athletes by exercising overloaded. In order to reduce DOMS, can given a combination of stretching and cold water with stretching and contrast water immersion. The purpose of this research is to prove which physiotherapy interventions is better for DOMS pain tolerance improvement. The research was carried out in the Ngurah Rai athletics field in Denpasar in January 2020, true experimental with a pretest and posttest two group design. Samples were male athletes divided into two groups, each group consisting of 9 respondents. Group I was given a combination of stretching and cold water immersion, Group II was given a combination of stretching and water immersion in contrast. Results in Group I, the mean pain tolerance before intervention was $153 \pm 7.76(\mathrm{mmHg})$ and the mean after intervention (48 hours) $206 \pm 8.32(\mathrm{mmHg})$ with $\mathrm{p}=0,000$. In Group II, the mean before intervention was $154 \pm 8.35(\mathrm{mmHg})$ and after intervention (48 hours) $188.4 \pm 6.95(\mathrm{mmHg}$ ) with a value of $\mathrm{p}=0,000$. This showed a significant increase in pain tolerance in each group. Statistical tests conducted between the two groups also showed significant differences, with a result of $p=0,000$, the value of pain tolerance in Group I was better than Group II. conclusion of the study is the combination of stretching and cold water immersion is better than the combination of stretching and contrast water immersion in reducing
\end{abstract} DOMS.

Keyword: Delayed onset muscle soreness; stretching; cold water; contrast water immersion; pain tolarance.

\section{INTRODUCTION}

Sport is an activity which is done to train body in order to stay in shape or a routine which is done to reach a certain purpose that is champhionship. The champhionship of Indonesia sports, especially athletics, still have to be improved which can be observed in test event of ASIAN Games 2018, Indonesia only could achieve 4 gold medals from 37 contested events. ${ }^{1}$ This can be affected by the athlete's lack of recovery. In athletics, an athlete can perform and compete in one until two matches in different events. If the recovery is not well-conducted in the first match, then it will cause a decrease in athlete's performance and on the top of that, DOMS can be caused by an injury. DOMS is one of discomfort due to pain in muscles, nerves and metabolism system after competing for 24 hours of competition and the peak of pain is in 72 hours and will gradually disappear on day 5 until day $7 .{ }^{2}$ When the athlete trains with excessive intensity, the fitness will increase but the fatigue will allow increase which can cause DOMS. ${ }^{3}$ In 3000 meters long distance running with duration 11 minutes, it uses predominant enegy system from aerobic and anaerobic energy system. While running with high intensity, in order to fulfil the amount of energy needed, muscles will increase its metabolism and produce lactic acid. For the athletes who never do training will prone to experiencing DOMS because the muscles contract excessively causinge damage to muscle tissue. Various methods can be used to overcome DOMS, such as the combination of stretching with cool water immersion and stretching with contrast water immersion.

Stretching is an activity which is performed to several group of muscles in order to regain muscle flexibility. ${ }^{4}$ Isotonic contraction which is performed during auto stretching of the tense and shortened 
mucles will get maximal mucles lengthening without resistance. Sarcomere lengthening occurs when the stretch is countinuous, so that the muscles will adapt and this is only temporarily lasted for the desired lengths of muscles. ${ }^{5}$

Cold water immersion which is performed in 10 minutes with immersion on the calf muscles (knee level) is to reduce fatigue and speed up post-workout recovery to prevent damage in the wider tissues. Cold theraphy will cause vasoconstriction, this will prevent and reduce inflammatory reaction occurs due to tissue damage after competition or training. ${ }^{6}$ Furthermore, cold water immersion can decrease tissue temperature and reduce the rate of chemical reactions. ${ }^{7}$ The reduction of chemical reaction causes a decrease in the demand of adenosine triphosphate (ATP) which reduces the need of oxygen and hypoxic effect.

Contrast water immersion is a themal modality where the certain body parts are alternaly immersed hot and cold water for temperature, time and duration to increase muscle strength, relieve muscle soreness and heal damaged mucles. ${ }^{8}$ In the research of Higgins (2011), immersion was carried out in 5 cycles, where in each contract cycle, 1 minute of water therapy was carried out effectively to accelerate recovery from rugby. ${ }^{8}$

Because of the importance of treating DOMS in athletes with short recoveries, investigators will consider better interventions between the combination of stretching with cold water immersion and stretching with contrast water immersion to improve pain tolerance and delay subsequent muscle soreness. ran 3000 meters. In a previous study conducted by Higgins (2013) stated that contrast bathing is a less effective strategy for recovery from rugby union than cold water immersion or passive recovery. In particular, 10-minute cold water immersion was better than contrast baths and passive recovery in reducing DOMS after training-induced muscle damage and recommended rugby union players to reduce the postgame effect of DOMS was cold water immersion for 10 minutes immediately after the match. In this study did not use passive recovery as a control group and combined stretching to immersion in cold water or contrast water, whereas in previous studies stretching was used as a measuring tool to detect DOMS.

\section{METHODS}

a. Methodology

This research is experimental research, with pretest and posttest two group design. The subject of this research is divided into two groups. In group I, the subject obtained intervention such as stretching and cold water immersion, meanwhile in group II, the subject obtained intervention, such as stretching and contrast water immersion. The research was occurred in Lapangan Atletik Ngurah Rai, Denpasar on $16^{\text {th }}-18^{\text {th }}$ January 2020.

The sampling techniques is based on the inclusion and exclusion criteria. The number of samples was 18 people, determined based on previous research conducted by Roewsell et all (2010) then it is divided into two groups. There are 9 people in each group, which is according to their age.

b. Material and procedure

The materials in this research are as follows:

1. Informed consent worksheet, which is used to discover willingness to be respondents.

2. Casio HS-3V-1RDT made in Japan with the accuracy 0,01 second.

3. Sphygmomanometer with Onemed 200 type made in Indonesia with the accuracy $+/-2$ $\mathrm{mmHg}$.

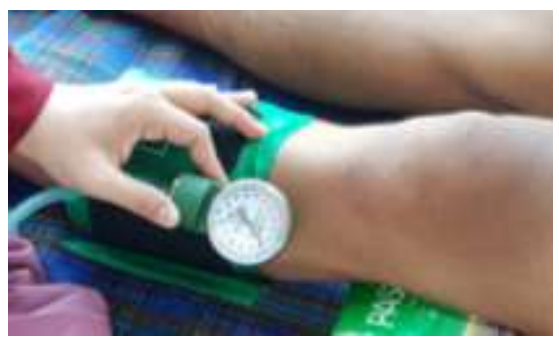

Figure 1. Sphygmomanometer with Onemed 200 
4. Krisbow infrared thermometer made in Indonesia with the accuracy $+/-2 \%$.

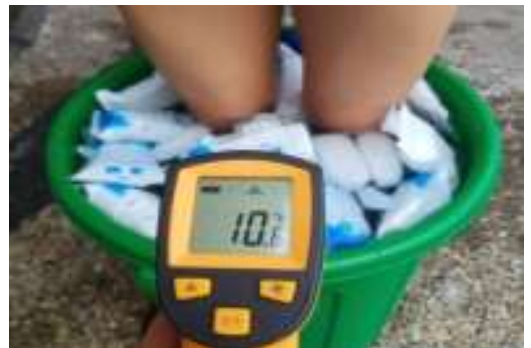

Figure 2. Krisbow infrared thermometer

5. 6 buckets to collect water.

6. Garmin Heartrate monitor with type Vivoactive 3 made in Taiwan.

7. Stationaries to write the data.

8. DOMS measurement form.

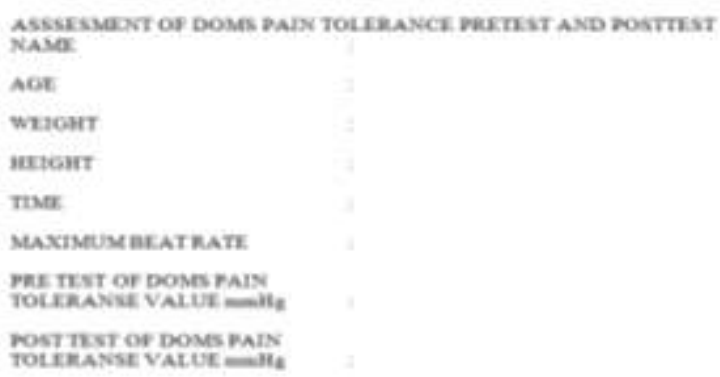

Figure 3. DOMS measurement form.

9. Camera to documentate the research activites.

The procedures in this research are:

1. Deciding the field for 3000 meters running.

2. Asking agreement to respondents (informed consent) by giving oral explanation about the research's aim and benefit as well as the right of respondents. The sample is in male category.

3. Dividing the sample in to 2 treatment groups, which are Group I has been given the combination of stetching and cold water immersion and group II has been given stretching and contrast water immersion.

4. Providing guidances to the sample about the aim and benefit of intervention given during the research and the procedures which must be followed during the research process. Before and after intervention.

5. Measuring the height and maximum pulse to determine the training intensity.

6. Warming up which is done by the atheletes, then they were asked to run for 3000 meters in 11 minutes (it was done alternately for group I and II).

7. After running for 11 minutes at maximum speed, measurements are taken with the pretest measurement, where the cuff sphygmomanometer is placed on the calf muscle then inflated until it expands. Pump the cuff to the pressure in the cuff until the subject feels the maximum pressure as the tolerance limit for calf muscle pain. Pay attention to the dynamometer needle when the subject feels pain. This figure is recorded in $\mathrm{mmHg}$. Then the cuff is slowly deflated and the cuff is removed from the subject's calf muscle.

8. Followed by stretching for 5 minutes, then immersed in cold water (group I) for 10 minutes with a water temperature of $10-15^{\circ} \mathrm{C},{ }^{7}$ done in a standing position and the legs were submerged at the knees. The same thing was done by Group II (immersion of contrast water) after stretching for 5 minutes then continued by soaking in warm water with a temperature of $36-400 \mathrm{C}$ for 60 seconds, then the subjects moved to a tub filled with cold water with a temperature of 10-15 0C was done repeatedly until it reaches 5 cycles, ${ }^{7}$ standing and submerged leg knees. 
9. Intervening in a combination of stretching with cold water immersion and stretching with contrast water immersion.

10. Re-measuring DOMS pain tolerance was performed at 48 hours.

11. Analizing data and concluding the research results.

c. Assessment

Respondents ran with a maximum speed of 11 minutes. Each respondent uses a heart rate monitor to control the running speed of each respondent. Running at a maximum speed for 11 minutes causes DOMS because the selected respondents have never practiced for 1 month so that during training there is an overload. DOMS pain tolerance measurements use a sphygmomanometer mounted on the calf with values above $100 \mathrm{mmHg}$. The higher the mmhg value, the higher the tolerance. ${ }^{9}$

d. Data analysis

After data was collected, the processing and analyzing data was done by IBM SPSS Statistics for windows, version 25 .

1. Normality test by using saphiro-wilk test. $p>0,05$ which means the data is normaly distributed.

2. Homogeneity test by using levene's test. $p>0,05$ which means the data is homogeneous.

3. Hypothesis test

a. The paired t-test to prove the results of hypotheses 1 and 2 aims to compare before and after giving stretching and cold water immersion with stretching and contrast water immersion in increasing pain tolerance in male athletic athletes who experience DOMS after running as far as 3000 meter. The research conducted showed $\mathrm{p}$ value <a $(0.05)$ so that there were differences in the effects before and after the intervention in group I and group II.

b. Independent $\mathrm{t}$-test to prove the hypothesis 3 . The results showed the $\mathrm{p}$ value ( $\operatorname{sig} 2$ tailed) $<0.05$, so there was a difference in effect between group I (stretching method and cold water immersion) and group II (stretching method). and contrast water immersion).

\section{RESULTS}

a. The description of research subject

Table 1. Distribution of subject data based on age, weight, height and BMI to the two groups $N=19$.

\begin{tabular}{llll}
\hline Subject Characteristics & $\begin{array}{l}\text { Group I } \\
(\text { Mean } \pm \text { SB })\end{array}$ & $\begin{array}{l}\text { Group II } \\
(\text { Mean } \pm \text { SB })\end{array}$ & p` \\
\hline Age (th) & $17,33 \pm 1,00$ & $17,55 \pm 0,88$ & 0,624 \\
Height $(\mathbf{c m})$ & $166,55 \pm 6,14$ & $164,44 \pm 3,91$ & 0,397 \\
Weight $(\mathbf{k g})$ & $59,77 \pm 2,54$ & $60,22 \pm 3,03$ & 0,740 \\
BMI & $21,63 \pm 1,88$ & $22,29 \pm 1,06$ & 0,379 \\
\hline
\end{tabular}

It indicates that the characterisctics, such as age, height, weight and body mass index from the two groups before training, there is no significance difference which is from the analysis result obtained value $p>0,05$. As the result, each of the group has similar physical characteristics and abilities.

b. Normality test

Table 2. Normality test results before and after DOMS pain tolerance measurement

\begin{tabular}{lll} 
& $\begin{array}{c}\text { Before } \\
(\text { Mean } \pm \text { SB })\end{array}$ & $\mathbf{P}$ \\
\hline Group I & $153,00 \pm 7,76$ & 0,448 \\
Group II & $154,00 \pm 8,35$ & 0,292 \\
\hline & After & \\
\hline Group I & Mean \pm SB $)$ & $\mathbf{P}$ \\
Group II & $206,00 \pm 8,32$ & 0,124 \\
\hline
\end{tabular}

Based on the data in Table 2, the result of normality test before and after DOMS pain tolerance measurement by using Saphiro wilk test indicates that the value is $p>0,05$. The data reveals the statical test on group I and II before and after intervention is normally distributed. 
c. Homogeneity test

Table 3. Homogeneity test results before DOMS pain tolerance measurement.

$\begin{array}{ll}\text { Group I } & \text { Group II } \\ (\text { Mean } \pm \text { SB }) & (\text { Mean } \pm \text { SB })\end{array}$

\begin{tabular}{lrrr}
\hline Before & $153,00 \pm 7,76$ & $154,00 \pm 8,35$ & 0,630
\end{tabular}

The result of homogeneity test using Levene Test is the value before DOMS pain tolerance measurement from table 5.4 shows that the two test relusts is $p>0,05$. The data indicates the statistical test result of two groups are homogeneous.

d. T-Test on the effect before and after training of two groups

Table 4. Different Test Results before and after DOMS pain tolerance measurement

\begin{tabular}{lcccc}
\hline & $\begin{array}{c}\text { Before } \\
(\text { Mean } \pm \text { SB) }\end{array}$ & $\begin{array}{c}\text { After 48 jam } \\
(\text { Mean } \pm \text { SB })\end{array}$ & T & p \\
\hline Group I & & & & \\
Group II & $153,00 \pm 7,76$ & $206,00 \pm 8,32$ & $-18,390$ & 0,000 \\
& $154,00 \pm 8,35$ & $188,44 \pm 6,95$ & $-13,507$ & 0,000
\end{tabular}

Based on the result of $t$-test, the average of group I and group II in Table 5.4, the value which is obtained is $p<0,05$. It indicates that the average in the result of two groups increase significantly $(\mathrm{p}<0,05)$ on DOMS pain in calf muscle with the inscreasing percentage in pain tolerance of each group, that is $25,7 \%$ in group I and $18 \%$ in group II.

e. T-test between groups

Table 5. Difference test results between groups after DOMS pain tolerance measurement

\begin{tabular}{lccc} 
& Kelompok I & Kelompok II & T \\
\hline $\begin{array}{l}\text { Sesudah } 48 \text { jam } \\
\text { (Rerata } \pm \text { SB) }\end{array}$ & $206,00 \pm 8,32$ & $188,44 \pm 6,95$ & 4,858 \\
$\begin{array}{l}\text { It is revealed in Table 5 that the mean difference between group I and II after the intervention is p=0,000, which means in each group, } \\
\text { the invervention that is significantly different has been applied ( }<<0,05) .\end{array}$
\end{tabular}

\section{DISCUSSION}

a. The Characteristics of research subject.

The sample represents the target population, 18 running athletes in Denpasar, aged $16-19$ years old. In this research, the sample is divided into 2 groups, such as 9 respondents who receive combination stretching intervention and cold water immersion; and 9 subjects who receive combination stretching intervention and contrast water immersion. The age average of research subjects is shown in Table 5.1 where group I (stretching and cold water immersion) is 17,33 years old and in group II (stretching and cold water immersion) is 17,55 years old. The weight average of each group I and II is $59,77 \mathrm{~kg}$ and $60,22 \mathrm{~kg}$. Furthermore, $166,55 \mathrm{~cm}$ and $164,44 \mathrm{~cm}$ are the height average in group I and II. The characteristics of two subject groups are in the similar condition, so that age, height and weight variable do not generate significant effect in this research. The statements above is strengthened with data analysis where the value $p>0,05$ means that each group has similar characteristics and abilities. The sample in this research is not the professional athlete, but the training routine is done when there is a coming up competition and the training is only done twice a week. When the research was conducted, the athletes had been resting for 3 weeks after the last championship which they participated in. Student's card is used to measure the age of respondents.

b. Stretching combination and cold water immersion can improve DOMS pain tolerance in calf muscle after a 3000 meter run.

The test in the first group by using paired t-test, $\mathrm{p}=0,000(\mathrm{p}<0,05)$ is obtained which means that there was a significant difference in pain tolerance before and after intervention of stretching combination and cold water immersion. This indicates that the intervention in group I provides a significant increase in pain tolerance to delayed onset muscle soreness of calf muscle with an increased percentage of pain tolerance is $25.7 \%$ (table 4 ).

Cold water immersion with the temperature $11-15^{\circ} \mathrm{C}$ is considered optimal and has positive impact in increasing DOMS pain tolerance. In acute injury, there is vasoconstriction in arterioles level and venules that lasts $5-15$ minutes. By providing cold water immersion, will cause vasoconstriction which can slow down the bleeding and allows the blood platelets to make repairs. ${ }^{10}$ Chemical reaction is 
occurred which cause vessels vasodilation. This vasodilation will bring more blood to the injured area and increase the blood vessels. The chemical reaction which triggers this vasodilation will remove the leukocytes and toxin that were left after injury. The blood circulation process which runs in the body allows it to inhibit the inflammatory process. The cells response coincides with the vascular response. The other chemical mediators also remind the body to send out leukocytes which use phagocytosis to do cleaning. Cold water immersion in $10-15$ minutes is more effective to reduce nerve conduction parameters. ${ }^{11}$ Pain is a subjective sensation and hinder the athlete's performance. Therefore, pain reduction is important for improving athlete's performance. ${ }^{12}$ Pain reception which is related with cold application is achieved through an anesthetic affect which is considered corresponds with decreased nerve conduction velocity (NCV). But, the temperature of skin surface must be lowered about $13,6^{\circ}$ C. ${ }^{11}$

c. Stretching combination and contrast water immersion can improve DOMS pain tolerance in calf muscle after a 3000 meter run.

The test in group II by using paired sampel $t$-test, the value is $\mathrm{p}=0,000(\mathrm{p}<0,05)$ which means there is a significance difference in pain tolerance before and after intervention of stretching combination and contrast water immersion in 48 hours. This indicates that the intervention in group II provides a significant increase in pain tolerance to delayed onset muscle soreness pada calf muscle.

Contrast water immersion for 1 minutes of warm immersion and 1 minutes of cold immersion in 5 cycles was significantly reduced pain perception in 24 hours to 72 hours after eccentric training. ${ }^{13}$ The treatment with alternate cold and warm water respectively induces peripheral vasoconstriction and vasodilation. ${ }^{8}$ There is a potential that the blood flows to muscles is lower after the cold application. ${ }^{8}$ It is caused by the activation of thermal nociceptors, which leads to changes in sympathetic nerve activity and consequently reduces arterial flow. ${ }^{8}$ From this, the physiological of cold water is presumed to be partly mediated through temperature redaction which is caused by microvascular blood flow around the damage area, which reduces edema and inflammatory induction. ${ }^{8}$

d. The combination of stretching and cold water Immersion has more positive impacts than stretching and contrast water immersion in improve DOMS pain tolerance in calf muscle after a 3000 meter run.

The research in group I where combination stretching intervention and cold water immersion water applied, it can be concluded that the increased DOMS pain tolerance in calf muscles is occurred in group I and II with $\mathrm{p}=0,000(\mathrm{p}<0.0 .05)$. The meaning of this value is that there is a significant difference between combination stretching intervention and cold water immersion compared to combination stretching intervention and contrast water immersion to the increasing pain tolerance in calf muscles.

Cold water immersion is better in improving DOMS pain tolerance than contrast water immersion. ${ }^{7}$ The use of cold water can provide an increase in athlete's recovery. ${ }^{16}$ The groups were given stretching intervention, where stretching can reduce tension in the muscles or tendon. ${ }^{5}$ Stretching exercises with isotonic contractions that are actively performed have caused a stretching of the soft tissue in muscles which affect muscles and sarcomeres are stretched without resistance and stimulate GTO optimally. ${ }^{4}$ The stretched muscle spindle and sarcomeres cause the stretch receptors become active so that muscle spindle stretches to the maximum muscle length. ${ }^{4}$ In order to prevent muscle damage the stretch receptors inform the length changes and how fast it is to the spinal cord which then delivered to the central nervous system and received by the stretch reflex will try resist the changes of mucles lengths, so overstretch is not occurred by contracting the stretched muscles. ${ }^{5}$ In this process, the muscles become relaxed, increase muscle flexibility and decrease the soreness of muscle. ${ }^{16}$

The combination of stretching and cold water immersion has been given to group I and caused vasoconstriction in blood vessels. ${ }^{7}$ When DOMS occurs, the tissue around the injured area or calf muscle change the structure of the tissue and metabolism. ${ }^{12}$ The changes in the damage or torn tissue structures will disrupt the muscle activity and can be maximally contracted. Muscle can experience inflammation, spasm, weakness which will affect movement that involves joints or other movements. ${ }^{14}$ Providing cold water immersion with appropriate duration and dose based on the degree of muscle damage will help to reduce the degree of muscle damage. ${ }^{6}$

The increase in DOMS pain tolerance in group I is better than in group II. This is because the intervention in group I can reduce the inflammatory response, because the effect of coldness can absorb 
tissue temperature so that the temperature decreases through the conduction mechanism. ${ }^{18}$ The main function of cold therapy is to absorb calories from the injured local area, so that the temperature decreased, the longer the therapy duration, it will cause deeper cold penetration. ${ }^{19}$ Physiologically, immersing in cold water for 10 minutes $\left(10{ }^{\circ} \mathrm{C}\right)$ will cause local vasoconstriction of arteries and veins. ${ }^{20}$ Vasoconstriction is caused by the reflex action of smooth muscle from stimulation of the muscular nervous system and extrication of epinephrine and norepinephine. ${ }^{19}$ Cold sensation can reduce excitability of free nerve, thereby decreasing sensitivity to pain stimuli. Cold application can also reduce the cell metabolic rate so that metabolic waste is reduced. ${ }^{18}$ Beside that, cold water immersion is easier to be absorb to the tissue compared to warm water. When muscles have experienced a decrease in temperature due to cold application, the cold effect is longer than the heat due to the presence of subcutaneous fat which acts as an insulator. On the other side, subcutaneous fat is the main barrier of cold energy to be absorbed to muscles. In individual with $2 \mathrm{~cm}$ of subcutaneous fat, cold energy can be absorbed to muscle tissue within 10 minutes. ${ }^{19}$ Meanwhile, in group II which was given the stretching intervention and contrast water immersion with immersion $5 \times 1$ minute has the exposure of cold water in a short time which will cause increase production of free radicals. The production of free radicals will increase oxidative stress, which will cause greater stress on the muscles and exceed when the muscles are active while doing sports. ${ }^{20}$ According to Elias et al., (2013), the use of cold temperatures can promote faster recovery than warm temperatures. Warm application can increase edema and inflammatory response and it is counterproductive to recovery. In contrast, cold exposure can cause a variety of positive physiological changes, including analgesia, reduce edema through reduced fluid diffusion, vascular permeability, decrease local vasoconstriction, as well as reduce acute inflammatory response from muscle breakdown.

\section{CONCLUSION}

The combination of stretching and cold water immersion with a combination of stretching and contrast immersion can improve pain tolerance in male athletic athletes who experience DOMS. However, the comparison shows that the combination of stretch and cold water immersion is better than the stretch and contrast of water. This is in line with the research objectives. The researchers suggest that a combination of stretching and cold water immersion can be applied to athletic athletes to improve DOMS pain tolerance and should be practiced immediately after exercise. The next researcher must perform a CK examination which aims to determine the level of creatine kinase in the blood.

\section{CONFLICT OF INTEREST}

The authors declare no conflict of interest

\section{ACKNOWLEGGEMENT}

My gratitude goes to all athletic athletes involved in this research, some of my friends who have helped in preparing the tools and materials in this research to Mr. Nyoman Suteja as the trainer of the athletes who supported this research.

\section{REFERENCES}

1. KEMENPORA. Ministry of Youth and Sports of Indonesia. 2019.http://www.kemenpora.go.id the Republic of.

2. Pearcey, Gregory E. P., David J. Bradbury-Squires, Jon Erik Kawamoto, Eric J. Drinkwater, David G. Behm, and Duane C. Button. Foam Rolling for Delayed-Onset Muscle Soreness and Recovery of Dynamic Performance Measures. J of Athletic Training. 2015;50(1):5-13.doi : 10.4085/10626050-50.1.01

3. Bomba, T.O., Harf, G.G. Periodization Theory and Methodology of Training. 5th Ed.Human Kinetics.

4. Cahyoko W. The Effect of Stretching Exercises on Dynamic Balance in Women Age 60-70 Years Old Club of Anggrek Karangpilang, Surabaya City. J of Sports Health. 2016;4 (1): 92- 97.

5. Kishner, C., Colby, L.A. Therapeutic Exercise Foundation \& Technique. 5 th Ed. 2007.

6. Viera. A., Siqueira, A.F., Ferreira, J.B., Carmo, J.L., Durigan, A., Blazevich, M. The Effect of Water Temperature during Cold-Water Immersion on Recovery from ExerciseInduced Muscle Damage. J Sports Medicine. 2016. doi:10.1055/s-0042-111438. 
7. Higgins, Trevor R., I. Tim Heazlewood, and Mike Climstein. A Random Control Trial of Contrast Baths and ICE Baths for Recovery during Competition in U/20 Rugby Union. J Strength and Conditioning Research. 2011;25(4):1046-51. doi: 10.1519/ JSC.0b013e3181cc269f.

8. Bieuzen, F., Chris, M. Bleakley., Joseph, T.C. Contrast Water Therapy and Exercise Induced Muscle Damage: A Systematic Review and Meta-Analysis. PLOS ONE . 2013;8(4).doi :10.1371/journal.pone.0062356.

9. Rahayu, N.P.C. 2018. "The Combination of Ultra Sound Therapy and Counterstrain Strain Is Better Than The Combination Of Ultra Sound Therapy And Foam Roller Calf Exercise To Reduce Myofascial Pain Calf Muscle Pain At Supermarkets Cashier In Denpasar" (thesis). Denpasar: Udayana University.

10. Machado, A.F., Ferreira, P.H., Michelletti, J.K., Almeida, A.C., Lemes, I.R., Vanderlei, F.M., Junior, J.N., Pastre, C.M. Can Water Temperature and Immersion Time Influence the Effect of Cold Water Immersion on Muscle Soreness? A Systematic Review and Meta-Analysis. J Sports Medicine. 2016;46(4):503-14.doi:10.1007/s40279-015-0431-7

11. Rupp, Kimberly A., Daniel C. Herman, Jay Hertel, and Susan A. Saliba. Intramuscular Temperature Changes during and after 2 Different Cryotherapy Interventions in Healthy Individuals. J Orthopaedic and Sports Physical Therapy.2012;42(8):731-37.

12. Rowsell, Greg J., Aaron J. Coutts, Peter Reaburn, and Stephen Hill-Haas. Effect of Post-Match Cold-Water Immersion on Subsequent Match Running Performance in Junior Soccer Players during Tournament Play. J Sports Sciences.2011;29(1):1-6. doi: 10.1080/02640414.2010.512640

13. Gregson, W., Allan, R., Holden, S., Phibbs, P., Doran, D., Campbell, I., Waldron, S., Joo, C.H., Morton, J. Postexercise Cold-Water Immersion Does Not Attenuate Muscle Glycogen Resynthesis. J Medicine and Science in Sports and Exercise. 2012;45(6):1174-81. doi: 10.1249/MSS.0b013e3182814462

14. Ingram, J., Dawson, B., Goodman, C., Wallman, K., Beilby, J. Effect of water immersion methods on post-exercise recovery from simulated team sport exercise. J Science and Medicine in Sport. 2010;12(3):417-421.

15. Arovah, N.I. Cold therapy in the Management of Sports Injuries." Yogyakarta: Thesis. Faculty of Sport Science.2010.

16. Bleakley, M., Davion, W. What is the biochemical and physiological rationale for using cold-water immersion in sport recovery? A systematic review. The American Journal Of Sports Medicine. 2012;44:179.

17. Elias, G., Varley, M.C., Wyckelsma, V., McKenna, M., J., Minahan, C, L., Aughey, R, J. Effects of Water Immersion on Posttraining Recovery in Australian Footballers. $j$ sports physiology and performance. 2012;7:357-366.doi: 10.1123/ijspp.7.4.357.

18. Griadhi, I.P.A. Biomolecular Adaptation of Skeletal Muscle Network Hypertrophy in Weight Training and Its Benefits in Metabolic Syndrome. J Sport And Fitness. 2019;7(4):72-79.

19. Higgins, Trevor R., I. Cameron,M.,L, Climstein., M. Acute Response To Hydrotherapy Game Of Rugby. J Strength and Conditioning Research. 2013;(10):2851-60. doi: 10.1519/ JSC.0b013e31828151b6. 